\title{
СУБЪЕКТИВНОЕ БЛАГОПОЛУЧИЕ ПОЖИЛОГО ЖИТЕЛЯ РОССИЙСКОГО ДОМА-ИНТЕРНАТА
}

\begin{abstract}
В работе рассмотрены особенности субъективного благополучия пожилых жителей одного их крупнейших домов-интернатов для престарелых и инвалидов Ростовской области. В контексте эвдемонической, оценочной и аффективной составляющих благополучия выбраны такие индикаторы как самооценка, идентичность, отношение к старению, удовлетворенность условиями, жизненная позиция, социальные связи, жизненные перспективы, контроль над жизнью. Среди актуальных проблем выделены типичные для пожилых россиян в целом (слабое здоровье, материальные трудности) и особые проблемы постояльца государственного стационара: отсутствие дома, нарушение и локализация социальных связей, зависимость от посторонней помощи, маломобильность, ощущение статичности жизни, отсутствие жизненных планов и перспектив, тревожность по поводу будущего. Маргинальный характер статуса жителя интерната повышает одни компоненты благополучия (чувство дома, интеграция) и снижает другие (контроль над жизнью). Соответственно, субъективные оценки постояльцев своего положения представлены в виде противоречивых дихотомий. Социальное сопровождение облегчает самообслуживание и адаптацию, но снижает уровень личной ответственности и контроля. Идентификация с интернатом способствует формированию чувства дома, но закрепляет некритичное отношение к условиям жизнедеятельности и «объектное» положение «иждивенца». Коммунальные условия проживания сглаживают риски одиночества, выступают основой взаимопомощи, но лишают личного пространства, свободы, самостоятельности. Такие составляющие благополучия как ощущение счастья,
\end{abstract}

Татьяна Сергеевна Киенко- к.с.н., доцент, заместитель директора по науке, Институт философии и социально-политических наук, Южный федеральный университет, Ростовна-Дону, Россия. Электронная почта: tskienko@sfedu.ru

Руфина Михайловна Рудакова - студентка, Южный федеральный университет, Ростовна-Дону, Россия. Электронная почта: rmihaylova@sfedu.ru 
уверенность в себе, способность контролировать жизнь, высокая оценка жизни и здоровья сопряжены с активной жизненной позицией постояльцев, оптимизмом, коммуникабельностью, мобильностью. Наличие жизненных перспектив прямо связано с качеством социальных контактов внутри и за пределами интерната. Задача преодоления амбивалентного статуса «старика, живущего в интернате» и негативных стереотипов требует создания условий и развития технологий поддержания позитивного самопонимания, самостоятельности, активности, свободы, мобильности, обеспечения доступной среды и конструктивных коммуникаций (дружеских, соседских, семейных), выхода пространства старения за физические и социальные границы интернатов.

Ключевые слова: пожилой человек, дом-интернат для престарелых и инвалидов, субъективное благополучие, Ростовская область

DOI: $10.17323 / 727-0634-2020-18-2-255-268$

Свыше 280 тыс. граждан пожилого возраста и инвалидов ежегодно получают социальные услуги в $\mathrm{COH}$ - стационарных учреждениях социального обслуживания населения (Росстат 2019). Необходимость переезда в стационар, как правило, обусловлена совокупностью «обстоятельств, которые ухудшают или могут ухудшить условия жизнедеятельности» (Федеральный Закон 2013: 15.4), ослаблением здоровья, утратой способности к самообслуживанию. Одновременно с этим принципы социальной модели инвалидности и старения ориентированы скорее на деинституциализацию, отказ от локализации уязвимых сообществ и их проблем в стенах стационаров (European Expert Group 2012). Однако наша страна вряд ли сможет полностью отказаться от интернатов. Это актуализирует задачу поиска действенных инструментов повышения благополучия пожилых жителей российских социальных стационаров.

В научной литературе, как правило, представлены описательные работы социально-технологической направленности или исследования частных случаев самочувствия пожилых постояльцев интернатов (Глущенко, Петрова 2017). Прорывом в этой области стало исследование «миров институциональной заботы» в пространстве пансионата для пожилых, исследование субъективных оценок самочувствия пожилых в этих заведениях (Здравомыслова, Низамова 2019; Шерстнева 2019). В статье развивается схожая оценка и проанализированы классические индикаторы благополучия пожилого человека в одном из российских домов-интернатов. Производится поиск факторов благополучия пожилых постояльцев российских социальных стационаров, условия и ресурсы его повышения.

\section{Индикаторы и особенности благополучия пожилых людей}

В зарубежных исследованиях субъективное благополучие (subjective well-being), благосостояние (welfare), удовлетворенность жизнью (satisfaction 
with life) рассматриваются в контексте концепций социального благополучия и счастья (DeJonge et al. 2016; Diener, Tay 2015; Diener et al. 1985). Российские социологи используют понятия социального настроения (Тощенко 1998), общественного благополучия (Воронин 2010; Воронин 2009), социального самочувствия, удовлетворенности жизнью, оптимизма, счастья (Воронин и др. 2018; Козырева, Смирнов 2017; Усова 2017; Козырева и др. 2015; Крупец 2003), субъективного благополучия (Шамионов, Бескова 2018; Зеликова 2014). При этом в структуре благополучия выделяются аффективная (счастье) и когнитивная (удовлетворенность) либо эвдемоническая (самооценка, контроль над жизнью, планы на будущее), оценочная (удовлетворенность) и аффективная (счастье, тревожность) составляющие. Таким образом, если учитывать совокупность всех элементов, выстраивается принцип «собъективности», т.е. интеграция субъективных и объективных показателей благополучия через их согласованность (Павлова и др. 2018: 25; Воронин 2010: 79-82).

К факторам благополучия пожилых людей можно отнести формы и условия проживания, занятость, социальную включенность, позитивные эмоции, сексуальные отношения. При этом снижение ощущения счастья, удовлетворенности жизнью объясняется не возрастом, а накапливающимися объективными утратами (Jivral et al. 2014). Поэтому исследователи выявляют нелинейность снижения благополучия пожилых россиян с возрастом (Воронин и др. 2018:42-43). Екатерина Настина видит ключевую роль возраста, дохода и социальной изоляции в благополучии россиян с инвалидностью (Nastina 2019: 623). Выделяются другие значимые факторы благополучия: удовлетворенность финансовым положением, оценка здоровья, свобода и самостоятельность, социальные отношения, контроль над жизнью (Зеликова 2014: 64-68; Крупец 2003).

С субъективной точки зрения, убеждение в собственной беспомощности перед процессами старения, бедностью, болезнями, утратами ведет к принятию негативных стереотипов старости, а чувство контроля над жизнью- к их отрицанию (Weiss 2018; Lachman, Weaver 1998). На благополучие в пожилом возрасте отрицательно влияют стрессы, а положительно- высокая самооценка и самоактуализация (Савенышева и др. 2019; Стрижицкая, Петраш 2016). Таким образом, оптимистичное восприятие собственного старения оказывает позитивное влияние на самооценку, а пессимистичное - негативное (Barrett, Toothman 2018; Bellingtier, Neupert 2018). Имеется связь благополучия пожилых с привычной окружающей средой, знакомым местом проживания, привязанностью к дому (Резниченко 2016; Sixsmith et al. 2014). Отсутствие дома усугубляет неустойчивость самооценки, отрицательно влияет на самочувствие (Szabo et al. 2018). Иными словами, локализация в специализированных пространствах рассматривается как фактор риска (Petersen, Warburton 2012), а положительно на благополучие влияют семейные отношения, общение с детьми 
и внуками (Momtaz et al. 2018; Huang 2012), включенность в группы и сообщества, соседские и дружеские взаимодействия (Evans 2009) даже в интернатах (Klaassens, Meijering 2015).

В этой работе мы проверяем эти выводы на примере одного из домов-интернатов для престарелых и инвалидов Ростовской области. Материалом для анализа субъективного благополучия стали опросы и интервью его постояльцев в 2017-2019 гг. В структуре благополучия выделены эвдемоническая, оценочная, аффективная составляющие и их индикаторы: особенности возрастной идентичности, отношение к старению, самооценка, уверенность в себе, оценка здоровья, способность самостоятельно решать проблемы, контроль над жизнью, удовлетворенность, социальные связи (дружба, коммуникация, поддержка), интересы, эмоциональные доминанты, досуговые практики, планы на будущее. В пилотном опросе (ноябрь 2017 г.) приняли участие 20 жителей геронтопсихиатрического отделения (10 женщин, 10 мужчин), в ноябре 2019 г. опрошены 48 респондентов отделения «Милосердие» (24 женщины, 24 мужчины). Отделения интерната отбирались целевым образом как типичные для российских социальных стационаров. Применялся метод интервью по формализованному опроснику и неформализованная беседа. Возраст респондентов составил от 60 до 95 лет, разброс в уровне пенсионного обеспечения около 2 тыс. руб. (75\% отчисляется в счет содержания). Большинство респондентов имеют соматические и первичные ментальные нарушения, затруднения в самообслуживании. Проживают на территории интерната круглосуточно (от двух до шести постояльцев в палате площадью 12-20 кв.м), имеют единые условия проживания и обслуживания.

\section{Особенности возрастной идентичности. Отношение к старению, оценка здоровья}

Жители геронтопсихиатрического отделения (2017) относят себя к «пожилым», людям «пенсионного», «элегантного», «почтенного» возраста (редко «преклонного», «старого»). Респонденты демонстрируют избирательность («пожилой», но не «старый»), относительность восприятия старости: «В 60 лет ты молод рядом с 70-летним соседом по палате, и стар рядом со студентом». Старость понимается как ослабление физического, социального и психологического здоровья вне биологического возраста, как субъективное экзистенциальное переживание: «Когда человек становится стар сердием и душой». Не высказывалось ни радости, ни страха от наступления старости.

Жители отделения «Милосердие» (2019) собственный возраст описывают как «пожилой», «зрелый», «юный» (только мужчины), «элегантный», реже «старый», «почтенный», «средний». Отношение к своему возрасту как оптимистичное («интересньй», «жить и жить», «не чувствую возраста»), 
так и пессимистичное («жизнь прошла», «плохо», «крепимся, живем потихоньку»). Пожилой возраст часто воспринимается позитивно: «это я», «радость», «жизнь сложилась, человек отдыхает, защищен семьей и детьми», «сила духа», «стремление кжизни», «общение, музыка и книги». В негативном ключе информанты высказывались реже: «физическая деятельность на спаде», «года прошли», «одиночество», «неизбежность», «нудньй, брезгливый и агрессивный». Все же со старостью связывались негативные ассоциации: «одни болезни», «слабость», «плохо», «жаль», «обида», «незащишщен», «ждешь смерти», «когда ничего не интересует», «а что хорошего? Годы-то идут». Хотя и наблюдается амбивалентное сочетание негативных стереотипов старости и позитивных пожилого возраста, идентичность с геронтогруппой (пожилой, но не старый).

Оценка здоровья выступает существенным элементом самооценки, она относительна оценки здоровья других постояльцев и их возраста: «Да ведь мне уже 95 лет, я 20 лет не хожу, а все равно живу и радуюсь». При этом отмечается важность динамики здоровья и самочувствия («с каждым днем труднее») и внешних условий («мне тут весело, все помогут, и соседи, и сотрудники, чего болеть, у нас палата дружная»). Объективное физическое состояние и календарный возраст не играют роли в оценке собственного здоровья. «Долгожители» и не способные к самостоятельному передвижению постояльцы оценивали себя как здоровых, в то время как более молодые и мобильные могли оценить свое здоровье как слабое. Значение скорее имели активная жизненная позиция и оптимизм: жители, считающие себя оптимистами, свой образ жизни активным и открытым, оценивали свое здоровье выше, чем респонденты, считающие себя пессимистами, ведущие пассивный образ жизни.

\section{Актуальные проблемы. Контроль над жизнью, самостоятельность и уверенность в себе}

В числе основных проблем респонденты отмечают ослабление здоровья, материальные осложнения и трудности самообслуживания. Реже назывались плохие отношения с родственниками, отсутствие продуктивной деятельности, образования, личной жизни, любви («некого любить», «не о ком заботиться»), общения и досуга «в кругу единомылиленников». Но о наличии сложностей большинство респондентов не сообщают: «все как у всех», «тут все хорошо, есть все что нужно», «вроде ничего».

Отсутствие дома- одна из значимых проблем. Респонденты мечтают вернуться домой, им не хватает «родных стен», «своего дома». Причинами поступления в дом-интернат являются, как правило, потеря жилья или конфликты с родственниками, материальные затруднения. Если жители «элитных» пансионатов принимают решение о поступлении в учреждение самостоятельно, часто исходя из соображений сохранения автономии 
(Здравомыслова, Низамова 2019; Шерстнева 2019), то в типовые интернаты поступают вынужденно. Лишаются жилья при передаче родственникам, в результате мошенничества, в силу социальных проблем, асоциального образа жизни, проживания в ветхом жилье, освобождения из мест лишения свободы. Проблемы отсутствия дома и нарушения связей с родственниками для жителей интерната являются значимыми, но латентными, редко артикулируются в форме жалобы и часто в рассказах о своей мечте: «Мечта у меня одна: так бы и пошла домой. Я уже тут больше 10 лет, дома нет у меня, да мне тут хорошо, все добрые, а мечтаю домой вернуться».

Важными факторами, влияющими на ощущения благополучия жителей интерната являются малая мобильность и зависимость от посторонней помощи: «Если бы я могла сама выйти на улииу - было бы совсем иначе все», «Я даже в коридор не могу выйти, какой тут у меня досуг». Пожилые люди отмечают, что зависят от внешних обстоятельств, самочувствия и погоды, окружения и компании, но почти все высоко оценивают собственные возможности самостоятельно решать проблемы и контролировать жизнь. Даже из числа немобильных постояльцев, не способных обойтись без помощи, лишь половина низко оценивают собственные возможности контролировать и менять жизнь. Это свидетельствует о потребности ощущать свободу, функциональность, и о необходимости расширения в повседневном пространстве интернатов локальных ситуаций принятия решений, самостоятельности, успеха.

Имеется связь между самооценкой, активностью и выделением актуальных проблем. Постояльцы, считающие себя оптимистами, свой образ жизни активным, говоря о своих проблемах, указывают не более одной, считают себя способными справляться без посторонней помощи, уверены в себе, чаще считают себя счастливыми. Пассивные «пессимисты» не чувствуют себя счастливыми. Неспособность решать жизненные трудности и контролировать жизнь сопряжена с заниженной оценкой своего здоровья и статуса, доминантой негативных стереотипов старости, пассивностью, отсутствием жизненных перспектив. Чем выше вовлеченность в социальные практики и общение (особенно за пределами дома-интерната), тем выше уверенность в способности контролировать свою жизнь. Жители, уверенные в том, что могут ее контролировать, положительно или нейтрально маркируют старение, называют больше радостных событий жизни, выше оценивают свой статус, здоровье, что схоже с данными Дэвида Вайса (Weiss 2018).

\section{Досуг, интересы, эмоциональные доминанты, планы на будущее}

Респонденты считают, что в жизни жителей дома-интерната нет никаких дел и событий, ничего не происходит, ни радостного, ни печального, их мир однообразен: «Какая у нас тут жизнь <...> вот у молодых- 
жизнь, а тут уже так, доживают». В интернате реализуются досуговые мероприятия, программы арт-терапевтической, реабилитационно-трудовой, спортивно-оздоровительной, психологической поддержки, социокультурного туризма. Но регулярно принимают участие в них не более половины жителей. Активные жильцы имеют увлечения (как правило, не более одного), хотя и предпочитают пассивные формы досуга (телевизор, радио, общение с родственниками и друзьями, чтение).

Некоторые постояльцы гуляют по территории интерната, посещают театры, музеи, мероприятия вне интерната. Немобильным жильцам трудно выходить из комнат. Постояльцы, у которых сложились плохие отношения с соседями, испытывают затруднения в возможностях чтения, просмотра телепередач на свой вкус. Ограничения выхода за пределы палат, интерната актуализируют задачу обеспечения доступной среды, сопровождающего персонала и волонтеров, что становится новым трендом проектов долговременного ухода. Повышению благополучия способствует также расширение зон уединения- например, персональное зонирование личных пространств (шторы, ширмы), расселение с учетом интересов, развитие досуговых технологий с помощью интернета, организации досуговых мероприятий в палатах.

У большинства жителей, независимо от жизненной позиции, отсутствуют планы на будущее, жизненные цели и перспективы: «Да какие у меня могут быть планы, мне 95», «дожить до 80 лет». Присутствует тревога по поводу своего текущего и будущего положения. Жизненные планы есть у поддерживающих социальные отношения с семьей, друзьями, волонтерами, посещающих музеи, театры, храмы. Однако у большинства внешних связей и поводов для радости нет. Развитие инструментов стимулирования взвешенных жизненных перспектив, расширение коммуникаций и событийности жизни-важнейший вопрос в организации работы с постояльцами интернатов.

\section{Удовлетворенность условиями жизни и социальное пространство}

Наполненное общением пространство повышает благополучие пожилого человека, а его отсутствие снижает самочувствие в любых условиях проживания. Жильцы интерната поддерживают отношения с родственниками, соседями по палате, персоналом интерната, но близких людей практически лишены. Помощь от специалистов постояльцы получают чаще, чем от соседей и родных. В качестве желательных субъектов помощи называют персонал, небольшое количество жильцов готовы принимать помощь от служителей церкви, волонтеров, детей, внуков. Это свидетельствует о слабости социальных связей, страхе перед новыми людьми и формами взаимодействия, доминанте формальных коммуникаций и недостатке эмоциональных привязанностей. 
Между персоналом и жителями интерната часто налаживаются доверительные отношения. Сотрудники и подопечные обмениваются шутками, тактильными проявлениями заботы, подарками и угощениями, что формирует атмосферу альтернативного дома. Однако персонал, как правило, занимает доминантную позицию опекающих, а благополучатели- позицию объектов заботы, что закрепляет их пассивность, снижает самостоятельность. Инициативу взаимодействия с персоналом проявляют жильцы с активной жизненной позицией и высоким образовательно-профессиональным статусом (бывшие руководители, чемпионы, врачи, учителя). Некоторые респонденты сообщают о проявлениях невнимания, грубости, формализма со стороны персонала, о ссорах между жильцами интерната, что актуализирует задачу создания конструктивного социального пространства старения.

При оценке качества жизни в доме-интернате и удовлетворенности различными ее аспектами информантами отмечается неопределенность их позиций, но часто они просто преувеличивают позитивность оценки условий или дают формальные ответы-критика звучит крайне редко. Напротив, выстраивается идентификация с интернатом. Жители считают неприличным говорить посторонним о проблемах, плохом самочувствии, стараются хвалить интернат, поддерживать его имидж, руководствуясь чувством солидарности. Высокая идентификация с интернатом повышает включенность в социальное пространство, формирует чувство дома, но закрепляет зависимость от него, объектность и самостигматизацию.

\section{Заключение}

Статус постояльца интерната противоречив. С одной стороны, он поддерживается такими компонентами благополучия как чувство дома и интегрированность, но снижается за счет утраты контроля над жизнью. Среди факторов, снижающих ощущение благополучия,- неопределенность жизненной стратегии и перспектив, локализация социальной жизни, ограниченность мобильности и свободы, статус объекта заботы. При этом жизнь в коллективе людей со сходной жизненной ситуацией и интересами способствует смирению и адаптации. Социальное сопровождение облегчает условия жизни, но закрепляет пассивность, объектность, снижает контроль над жизнью. Коммунальное проживание сглаживает риски одиночества, но лишает личного пространства и возможности уединения.

Активная жизненная позиция, оптимизм, коммуникабельность и мобильность выступают ключевыми факторами повышения самооценки, ощущения счастья, уверенности в себе, способности контролировать жизнь. Риски снижения благополучия выше для жителей с пассивным отношением. Включенность в разнообразные практики, дружба, наличие родственных связей способствуют формированию жизненных перспектив и росту благополучия. 
Создание конструктивного социального пространства старения и развитие внеинтернатных форм жизнедеятельности- необходимая часть организации жизни в интернате. Рост благополучия может стимулировать развитие утраченных и альтернативных семейных отношений, коммуникаций внутри и вне интерната, межпоколенческих проектов. Таким образом, в задачи социальной политики в этом отношении включается стимулирование активности, субъектности, самостоятельности, контроля над жизнью, повышение мобильности.

\section{Выражение признательности}

Авторы благодарят Южный федеральный университет, при поддержке которого выполнена данная работа; студентов и сотрудников кафедры социальных технологий ЮФУ, принимавших участие в исследовании; респондентов, администрацию и персонал дома-интерната за возможность познакомиться с их миром и увидеть результаты предложенных изменений.

\section{Список источников}

Воронин Г. Л. (2009) Объективные и субъективные показатели общественного благополучия. Социологические исследования, (3): 41-54.

Воронин Г. Л. (2010) Общественное благополучие: корреляция объективных и субъективных факторов. Россия и современный мир, 1 (66): 71-83.

Воронин Г. Л., Захаров В. Я., Козырева П. М. (2018) Одинокие пожилые: доживают или активно живут? Социологический журнал, 24 (3): 32-55.

Глущенко О. П., Петрова Н. В. (2017) Средства массовой информации как детерминанта психологической тревожности людей пожилого возраста. Общество и право, 4 (62): 258-262.

Зеликова Ю.А. (2014) Субъективное благополучие пожилых людей (кросс-национальный анализ). Социологические исследования, (11): 60-69.

Здравомыслова Е., Низамова А. (2019) Миры институциональной заботы: совместное проживание и конфликты в пансионате для людей старшего возраста. Е. Бороздина, Е. Здравомыслова, А. Темкина (ред.) Критическая соичология заботы: перекрестки социального неравенства. СПб.: Изд-во Европейского университета в Санкт-Петербурге: $217-252$.

Козырева П. М., Низамова А.Э., Смирнов А. И. (2015) Счастье и его детерминанты. Социологические исследования, (12): 120-132.

Козырева П. М., Смирнов А.И. (2017) Российские пенсионеры в условиях кризиса. Соииологические исследования, (1): 64-73.

Крупец Я.Н. (2003) Социальное самочувствие как интегральный показатель адаптированности. Соииологические исследования, (4): 143-144. 
Павлова И., Монастырный Е., Гуменников И., Барышева Г. (2018) Российский индекс благополучия старшего поколения: методология, методика, апробация. Журнал исследований сочиальной политики, 16 (1):23-36.

Резниченко С.И. (2016) Валеологический потенциал привязанности к дому у взрослых людей. Клиническая и специальная психология, 5 (3): 1-23.

Росстат (2019) Стационарные организации соииального обслуживания для граждан пожилого возраста и инвалидов. Доступно по ссылке: https://www.gks.ru/folder/13877 (дата обращения: 31 декабря 2019).

Савенышева С.С., Головей Л.А., Петраш М.Д., Стрижицкая О. Ю. (2019) Самоактуализация, психологическое благополучие и повседневный стресс в период взрослости. Вестник КемГУ, 21 (1): 130-140.

Стрижицкая О. Ю., Петраш М. Д. (2016) Повседневный стресс и особенности самооценки в разные периоды взрослости. Проблемы Науки, 38 (80): 108-110.

Тощенко Ж. Т. (1998) Социальное настроение- феномен современной социологической теории и практики. Социологические исследования, (1):21-35.

Усова Е.Н. (2017) Социальное самочувствие: теоретико-методологические подходы к исследованию (обзор). Саратовский научно-медицинский журнал, 13 (3): 554-559.

Федеральный Закон (2013) Об основах социального обслуживания граждан в Российской Федеращии № 442-ФЗ от 28.12.2013.

Шерстнева Н. (2019) Выбор пожилыми институциональной заботы как биографический проект (на материалах эмпирического исследования). Е. Бороздина, Е. Здравомыслова, А. Темкина (ред.) Критическая сочиология заботы: перекрестки социального неравенства. СПб.: Издательство Европейского университета в СанктПетербурге: 252-277.

Шамионов Р. М., Бескова Т.В. (2018) Методика диагностики субъективного благополучия личности. Психологические исследования, 11 (60). Доступно по ссылке: http://psystudy.ru/index.php/num/2018v11n60/1602-shamionov60.html (дата обращения: 2 ноября 2019).

Barrett A.E., Toothman E.L. (2018) Multiple «Old Ages': The Influence of Social Context on Women's Aging Anxiety. The Journals of Gerontology: Series B, 73 (8): 154-164.

Bellingtier J.A., Neupert Sh.D. (2018) Negative Aging Attitudes Predict Greater Reactivity to Daily Stressors in Older Adults. The Journals of Gerontology: Series B, 73 (7): 1155-1159.

DeJonge T., Veenhoven R., Kalmijn W., Arends L. (2016) Pooling Time Series Based on Slightly Different Questions About the Same Topic: Forty Years of Survey Research on Happiness and Life Satisfaction in The Netherlands. Social Indicators Research, (126): 863-891.

Diener E., Emmons R. A., Larsen R. J., Griffin S. (1985) The Satisfaction with Life Scale. Journal of Personality Assessment, 49 (1): 71-75.

Diener E., Tay L. (2015) Subjective Well-Being and Human Welfare Around the World as Reflected in the Gallup World Poll. International Journal of Psychology, 50 (2): 135-149. 
European Expert Group (2012) Common European Guidelines on the Transition from Institutional to Community-based Care. European Expert Group on the Transition from Institutional to Community-based Care. Available at: https://deinstitutionalisationdotcom.files.wordpress. com/2017/07/guidelines-final-english.pdf (accessed 12 December 2019).

Evans S. (2009) 'That Lot Up There and Us Down Here': Social Interaction and a Sense of Community in a Mixed Tenure UK Retirement Village. Ageing and Society, 29 (2): 199-216.

Huang Y. (2012) Family Relations and Life Satisfaction of Older People: A Comparative Study between Two Different Hukous in China. Ageing and Society, 32 (1): 19-40.

Jivraj S., Nazroo J., Vanhoutte B., Chandola T. (2014) Aging and Subjective Well-Being in Later Life. The Journals of Gerontology: Series B, 69 (6): 930-941.

Klaassens M., Meijering L. (2015) Experiences of Home and Institution in a Secured Nursing Home Ward in the Netherlands: A Participatory Intervention Study. Journal of Aging Studies, (34): 92-102.

Lachman M.E., Weaver S.L. (1998) The Sense of Control as a Moderator of Social Class Differences in Health and Well-being. Journal of Personality and Social Psychology, (74): 763-773.

Momtaz Y.A., Vidouje M. M., Foroughan M., Sahaf R. and Laripour R. (2018) Grandparents- Grandchildren Relationship in Iran, 2017. Clinical Practice and Epidemiology in Mental Health, (14): 296-303.

Nastina E. A. (2019) Subjective Well-Being and Disability in Russia: the Test of the Social Model. The Journal of Social Policy Studies, 17 (4): 615-628.

Petersen M., Warburton J. (2012) Residential Complexes in Queensland, Australia: A Space of Segregation and Ageism? Ageing and Society, 32 (1):60-84.

Sixsmith J., Sixsmith A., Fänge A.M., Nauman D., Kucsera C., Tomson S., Haak M., Dahlin-Ivanoff S., Woolrych R. (2014) Healthy Ageing and Home: The Perspectives of Very Old People in Five European Countries. Social Science \& Medicine, (106): 1-9.

Szabo A., Allen J., Alpass F., Stephens Ch. (2018) Longitudinal Trajectories of Quality of Life and Depression by Housing Tenure Status. The Journals of Gerontology: Series B, 73 (8): $165-174$.

Weiss D. (2018) On the Inevitability of Aging: Essentialist Beliefs Moderate the Impact of Negative Age Stereotypes on Older Adults' Memory Performance and Physiological Reactivity. The Journals of Gerontology: Series B, 73 (6): 925-933. 
Tatyana Kienko, Rufina Rudakova

\section{THE SUBJECTIVE WELL-BEING OF ELDERLY RESIDENTS IN RUSSIAN NURSING HOMES}

This article examines the subjective well-being of elderly people living in one of the largest nursing homes for the elderly and disabled in Rostov region, Russia. Firstly, we trace various approaches to well-being in social science and medicine. As a result of the review, a number of indicators are revealed to be used in further analysis. Secondly, we scrutinize whether these indicators are relevant to our interviewees. We conducted 68 structured and semistructured interviews with elderly residents of the care home. Among current problems of the residents are typical ones for other older Russians in general such as poor health and financial difficulties. However, they also experience specific problems as inhabitants of a nursing home: they long for their own home, miss connections with relatives, and are dependent on outside help, and suffer from immobility. Residents of the nursing home experience a sense of static life, a lack of life goals and prospects, and anxiety about their own future. Active attitudes in life, optimism, sociability, and mobility are associated with feelings of happiness, self-confidence, the ability to control one's life, as well as higher assessment of one's health and well-being. The availability of life prospects is related to the quality of social contacts inside and outside the nursing home. The marginal nature of the residential status increases some components of well-being (a sense of home, integration) and reduces others (control over life). The task of overcoming the ambivalent status of nursing home residents can be achieved by creating conditions and developing technologies to maintain independence, freedom and mobility, as well as to provide an accessible environment and expand social connections beyond the physical and social boundaries of nursing homes.

Keywords: elderly person, nursing home for aged and disabled people, subjective well-being, Rostov region of Russia

DOI: $10.17323 / 727-0634-2020-18-2-255-268$

\section{References}

Barrett A.E., Toothman E.L. (2018) Multiple 'Old Ages': The Influence of Social Context on Women's Aging Anxiety. The Journals of Gerontology: Series B, 73 (8): 54-164.

Bellingtier J.A., Neupert Sh.D. (2018) Negative Aging Attitudes Predict Greater Reactivity to Daily Stressors in Older Adults. The Journals of Gerontology: Series B, 73 (7): 1155-1159.

Tatyana S. Kienko- PhD (Sociology), Associate Professor, Deputy Director for Science, Institute of Philosophy and Socio-Political Sciences, Southern Federal University, Rostov-on-Don, Russian Federation. Email: tskienko@sfedu.ru

Rufina M. Rudakova- student, Institute of Philosophy and Socio-Political Sciences, Southern Federal University, Rostov-on-Don, Russian Federation. Email: rmihaylova@sfedu.ru 
DeJonge T., Veenhoven R., Kalmijn W., Arends L. (2016) Pooling Time Series Based on Slightly Different Questions About the Same Topic: Forty Years of Survey Research on Happiness and Life Satisfaction in The Netherlands. Social Indicators Research, (126): 863-891.

Diener E., Emmons R. A., Larsen R. J., Griffin S. (1985) The Satisfaction with Life Scale. Journal of Personality Assessment, 49 (1): 71-75.

Diener E., Tay L. (2014) Subjective Well-Being and Human Welfare around the World as Reflected in the Gallup World Poll. International Journal of Psychology, 50 (2): 135-149.

European Expert Group (2012) Common European Guidelines on the Transition from Institutional to Community-based Care. European Expert Group on the Transition from Institutional to Community-based Care. Available at: https://deinstitutionalisationdotcom.files.wordpress. com/2017/07/guidelines-final-english.pdf_(accessed 12 December 2019).

Evans S. (2009) 'That Lot Up There and Us Down Here': Social Interaction and a Sense of Community in a Mixed Tenure UK Retirement Village. Ageing and Society, 29 (2): 199-216.

Federal Law (2013) Ob osnovax social'nogo obsluzhivaniya grazhdan v Rossijskoj Federacii [On the Basics of Social Services for Citizens in the Russian Federation] N 442-FZ from 28.12.2013.

Glushchenko O.P., Petrova N.V. (2017) Sredstva massovoj informacii kak determinanta psixologicheskoj trevozhnosti lyudej pozhilogo vozrasta [Mass Media as a Determinant of Psychological Anxiety of Elderly People]. Obshhestvo i pravo [Society and Law], 4 (62): 258-262.

Huang Y. (2012) Family Relations and Life Satisfaction of Older People: A Comparative Study Between Two Different Hukous in China. Ageing and Society, 32 (1): 19-40.

Jivraj S., Nazroo J., Vanhoutte B., Chandola T. (2014) Aging and Subjective Well-Being in Later Life. The Journals of Gerontology: Series B, 69 (6):930-941.

Klaassens M., Meijering L. (2015) Experiences of Home and Institution in a Secured Nursing Home Ward in the Netherlands: A Participatory Intervention Study. Journal of Aging Studies, DOI: https://doi.org/10.1016/j.jaging.2015.05.002.

Kozyreva P. M., Nizamova A.E., Smirnov A. I. (2015) Schast'e i ego determinanty' [Happiness and Its Determinants]. Sociologicheskie issledovaniya [Sociological Research], (12): 120-132.

Kozyreva P.M., Smirnov A.I. (2017) Rossiyskie pensionery v usloviyakh krizisa [Russian Pensioners in Conditions of Crisis]. Sotsiologicheskie issledovaniya [Sociological Research], (1):64-73.

Krupets Ya.N. (2003) Social'noe samochuvstvie kak integral'ny'j pokazatel' adaptirovannosti [Social Well-being as an Integral Indicator of Adaptability]. Sociologicheskie issledovaniya [Sociological Research], (4): 143-144.

Lachman M.E., Weaver S. L. (1998) The Sense of Control as a Moderator of Social Class Differences in Health and Well-being. Journal of Personality and Social Psychology, (74): 763-773.

Momtaz Y. A., Vidouje M.M., Foroughan M., Sahaf R., Laripour R. (2018) Grandparents- Grandchildren Relationship in Iran, 2017. Clinical Practice and Epidemiology in Mental Health, (14): 296-303.

Nastina E.A. (2019) Subjective Well-Being and Disability in Russia: The Test of the Social Model. The Journal of Social Policy Studies, 17 (4): 615-628.

Pavlova I., Monastyrny E., Gumennikov I., Barysheva G. (2018) Rossijskij indeks blagopoluchiya starshego pokoleniya: metodologiya, metodika, aprobaciya. [Russian Index of Well-being of the Older Generation: Methodology, Methodology, Approbationn]. Zhurnal Issledovanii Sotsial'noi Politiki [The Journal of Social Policy Studies], 16 (1):23-36.

Petersen M., Warburton J. (2012) Residential Complexes in Queensland, Australia: A Space of Segregation and Ageism? Ageing and Society, 32 (1): 60-84.

Reznichenko S. I. (2016) Valeologicheskiy potentsial privyazannosti k domu u vzroslykh lyudey [Valeological Potential of Home Attachment in Adults]. Klinicheskaya i spetsial'naya psikhologiya [Clinical and Special Psychology], 5 (3): 1-23. 
Rosstat (2019) Stacionarnye organizacii social'nogo obsluzhivaniya dlya grazhdan pozhilogo vozrasta i invalidov [Stationary Social Service Organizations for Elderly and Disabled People]. Available at: https://www.gks.ru/folder/13877 (accessed 31 December 2019).

Savenysheva S. S., Golovey L.A., Petrash M.D., Strizhitskaya O. Yu. (2019) Samoaktualizaciya, psixologicheskoe blagopoluchie i povsednevny'j stress v period vzroslosti. [Self-Actualization, Psychological Well-being and Everyday Stress During Adulthood]. Vestnik KemGU [Bulletin of the KemSU], 21 (1): 130-140.

Shamionov R.M., Beskova T.V. (2018) Metodika diagnostiki sub"ektivnogo blagopoluchiya lichnosti [Method of Diagnostics of Subjective Well-being of the Individual]. Psixologicheskie issledovaniya [Psychological Research]. Available at: http://psystudy.ru/index.php/num/2018v11n60/1602shamionov60.html (accessed 2 November 2019).

Sherstneva N. (2019) Vy'bor pozhily'mi institucional'noj zaboty kak biograficheskij proekt (na materialax empiricheskogo issledovaniya) [Elderly People's Choice of Institutional Care as a Biographical Project (Based on Empirical Research)]. In: E. Borozdina, E. Zdravomyslova, A. Temkina (eds.) Kriticheskaya sociologiya zaboty': perekrestki social'nogo neravenstva [Critical Sociology of Care: Intersections of Social Inequality]. St. Petersburg: European University at St. Petersburg Press: 252-277.

Sixsmith J., Sixsmith A., Fänge A.M., Nauman D., Kucsera C., Tomson S., Haak M., DahlinIvanoff S., Woolrych R. (2014) Healthy Ageing and Home: The Perspectives of Very Old People in Five European Countries. Social Science \& Medicine, (106): 1-9.

Strizhitskaya O. Yu., Petrash M.D. (2016) Povsednevny’j stress i osobennosti samoocenki v razny'e periody vzroslosti [Everyday Stress and Features of Self-esteem in Different Periods of Adulthood]. Problemy' Nauki [Problems of Science], 38 (80): 108-110.

Szabo A., Allen J., Alpass F., Stephens Ch. (2018) Longitudinal Trajectories of Quality of Life and Depression by Housing Tenure Status. The Journals of Gerontology: Series B, 73 (8): 165-174.

Toshchenko Zh.T. (1998) Social'noe nastroenie - fenomen sovremennoj sociologicheskoj teorii i praktiki [Social Mood. A Phenomenon of Modern Sociological Theory and Practice]. Sociologicheskie Issledovaniya [Sociological Research], (1):21-35.

Usova E.N. (2017) Social'noe samochuvstvie: teoretiko-metodologicheskie podxody k issledovaniyu (obzor) [Social Well-being: Theoretical and Methodological Approaches to Research (Review)]. Saratovskij nauchno-medicinskij zhurnal [Saratov Journal of Medical Research], 13 (3): 554-559.

Voronin G. L. (2009) Ob"'ektivny'e i sub"ektivny'e pokazateli obshhestvennogo blagopoluchiya [Objective and Subjective Indicators of Social Well-being]. Sociologicheskie issledovaniya [Sociological Research], (3): 41-54.

Voronin G.L. (2010) Obshhestvennoe blagopoluchie: korrelyaciya ob'ektivnyx i sub"ektivny`x faktorov [Social Well-Being: Correlation of Objective and Subjective Factors]. Rossiya I Sovremenny'j Mir [Russia and the Modern World], 1 (66): 71-83.

Voronin G. L., Zakharov V. Ya., Kozyreva P. M. (2018) Odinokie pozhily'e: dozhivayut ili aktivno zhivut? [Lonely Elderly: Living out One's Days or Actively Living?]. Sociologicheskij zhurnal [Sociological Journal], 24 (3):32-55.

Weiss D. (2018) On the Inevitability of Aging: Essentialist Beliefs Moderate the Impact of Negative Age Stereotypes on Older Adults' Memory Performance and Physiological Reactivity. The Journals of Gerontology. Series B, 73 (6): 925-933.

Zdravomyslova E., Nizamova A. (2019) Miry institucional'noj zaboty': sovmestnoe prozhivanie i konflikty v pansionate dlya lyudej starshego vozrasta. [Worlds of Institutional Care: Cohabitation and Conflicts in a Boarding House for Older People]. In: E. Borozdina, E. Zdravomyslova, A. Temkina (eds.) Kriticheskaya sociologiya zaboty: perekrestki social nogo neravenstva [Critical Sociology of Care: Intersections of Social Inequality]. St. Petersburg: European University at St. Petersburg Press:217-252.

Zelikova Yu. A. (2014) Sub'ektivnoe blagopoluchie pozhily'x lyudej (kross-nacional'ny'j analiz). [The Subjective Well-being of Elderly People (Cross-National Analysis)]. Sociologicheskie issledovaniya [Sociological Research], (11):60-69. 